\title{
Cybersyn, big data, variety engineering and governance
}

\author{
Raul Espejo ${ }^{1}$
}

Received: 15 November 2020 / Accepted: 15 October 2021 / Published online: 4 January 2022

(c) The Author(s), under exclusive licence to Springer-Verlag London Ltd., part of Springer Nature 2022

\begin{abstract}
This contribution offers reflections about Chilean Cybersyn, 50 years ago. In recent years, Cybersyn, has received significant attention. It was the brainchild of Stafford Beer, who conceived it to support the transformation of the Chilean economy from its bureaucratic history to hopefully create a vibrant and modern society, driven by cybernetic tools. These aspects have received much attention in recent times; however, in this contribution, I want to discuss how working in Cybersyn influenced my work after the coup of 1973. Perhaps, for me, its major influence was in the management of complexity, through what I refer here as variety engineering and through the Viable System Model VSM as a paradigm to the management of relationships with implications to enterprises, society and the economy. After the 1973 coup major interest was in technological aspects of Cybersyn such as real-time management and its contribution to decision support and executive information systems. In the late 70s I was personally influenced by information management, but by the early 1980s my work moved towards methodological aspects of how to use the VSM. By 1989 I had created the VIPLAN method (Espejo, 1989). Key questions I attempted to answer were, how to model the complexity of enterprises and their interactions with environmental agents. Later on, in the 1990s and 2000s, the main direction of my work was epistemological, ontological and methodological towards second-order cybernetics and relationships. Only in recent decades the political transformations proposed by Cybersyn have captured the imagination of many commentators. The confluence of social and cultural changes with information technology, data models, artificial intelligence, algorithms and several additional technological developments have challenged the excesses of capitalism, particularly after the banking crisis of 2008-2009. The purpose in this paper is discussing this evolution in the light of those early days in Chile.
\end{abstract}

Keywords Cybersyn $\cdot$ Management cybernetics $\cdot$ Governance $\cdot$ Real time management $\cdot$ Economic cybernetics $\cdot$ Variety engineering $\cdot$ Viplan

\section{The Chilean project 1971-1973}

"Political questions are far too serious to be left to the politicians." Hannah Arendt

\subsection{About cybernetics and Stafford Beer}

My work in organisational cybernetics has evolved from the early work for the Chilean government to its application to small and large enterprises in Europe and Latin America, going to its more mature face today in the context of the

Raul Espejo

r.espejo@syncho.org

1 Syncho Research, World Organisation of Systems and Cybernetics (WOSC), Academician of the International Academy for Systems and Cybernetics, Lincoln, UK
World Organisation of Systems and Cybernetics WOSC and Syncho Research.

Cybersyn developments were guided by Salvador Allende's election as president of Chile in 1970 and conceptually by the Viable System Model VSM (Beer 1972, 1979, 1981, 1985).

The experience in Chile helped clarify methodological aspects of how to use management cybernetics to discuss governance in general. My work was at Chile's National Development Corporation. The Corporación de Fomento de la Producción-CORFO was created in 1939. In the initial period, it was an overarching and powerful institution that participated in the funding of over $30 \%$ of Chilean investment in equipment and machinery and $25 \%$ of public investment. Through many instruments, it played a key role in the process of Chilean economic development, including the creation of many key enterprises and playing an essential 
role in running these (Griffith-Jones et al. 2018). Following Allende's presidential election in 1970, Fernando Flores was appointed CORFO's General Technical Manager, responsible for a growing number of state owned enterprises, as the country nationalised its industry, particularly of medium sized companies. With my knowledge of CORFO's regional activities and the fact that regions were among Flores's responsibilities, we had plenty of opportunities to extend our conversations beyond them as we travelled along the country. He was aware of Stafford Beer's management cybernetics (Beer 1966) and our conversations evolved beyond the prevailing centralised economic management strategies of the main political parties, into new forms of organisation and management. These conversations were the starting point for an understanding of CORFO's possible activities in the new situation. Conversations with Jorge Barrientos, Humberto Gabella and several others were pivotal at these early stages. These were the people that formed the initial team that Stafford met in his first visit to Chile in November, 1971.

At that stage my personal knowledge of systemic thinking and cybernetics was indeed limited. Early conversations with Beer in 1971 helped me differentiate information and communications. I could see the shortcomings of information systems driven by historical data rather than by people's communications and conversations. I also started to pay attention to sensory- motor correlations and circular management as key for decisions (Beer 1972). The practice of real-time started to evolve in my mind, beyond the historic recordings of past events, which in practice meant no more than the accumulation of reports in managers' in-trays.

Two aspects of my work with Stafford have remained in my mind ever since. Naturally the VSM was one, which was proposed in his paper about aborting planning in 1969 (Beer 1969) before writing Brain of the Firm (1972). This model has been central to my work ever since. I will say in this article much more about its methodological and ontological developments. The second one implicit in our conversations throughout the project was A Model of Capitalism. Stafford wrote about this model in June of 1973, as we were approaching the end of the project Cybersyn and the coup was inexorably progressing towards the 11th of September 1973. That model of capitalism had been in his mind for some time, but it was in the peaceful environment of Las Cruces, beach near Santiago, where he stayed for more than a month, during his last visit to Chile, where he wrote its manuscript, accompanied by a set of cybernetic diagrams. I return to this work in social and economic cybernetics at the end of this paper.

Current developments in digital technology, particularly big data, artificial intelligence and algorithms, are deeply related to the Viable System Model, as I explore here related to the concept of variety, which is offered as a measurement of complexity, and to design, which is referred to here as

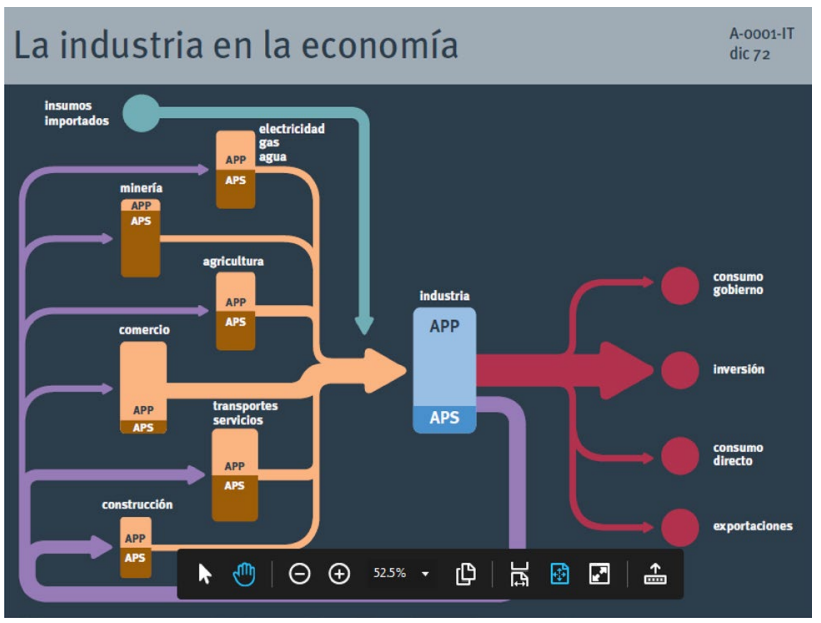

Fig. 1 Quantified flowchart of the industrial economy. Own source, according 1973 INTEC Corfo

variety engineering. Furthermore this model helps explore the embodiment of organisational relationships and visualising possibilities for new forms of social organisation as suggested by the model of capitalism. The paper concludes with reflections about current social developments, driven by digital technology, complexity management, organisational systems and relationships.

\subsection{My methodological beginnings with the viable system model VSM}

Stafford arrived in Chile with a manuscript of the Brain of the Firm, the first of four books he wrote about the VSM (Beer 1972, 1979, 1981, 1985). He had already handed over this manuscript to Allan Lane, The Penguin Press, for publication and I received it from his hands in November 1971, and asked for its translation, copying and distribution to all the early participants in the project. Afterwards, I received directly from him a copy of the published version of Brain of the Firm in February of 1972. It was pivotal to the learning that unfolded in the context of the Cybersyn group. Indeed this learning was not easy. The group had the benefit of several long sessions with him, where he explained the model. My learning also had the benefit of personal conversations with him about it and the situation in CORFO. I shared this understanding of the book with the rest of the team. This was a process of conceptual clarification about its application to the economy, starting from quantified flowcharts of the activities of enterprises in the industrial economy (see Fig. 1). This was a process of methodological clarification. We all needed this clarification of enterprises as organisational systems. The VSM and its systemic functions -systems $1,2,3,4$ and 5 in his terms- were necessary tools to model 
the industrial economy (Beer 1981). Often, people understood the VSM in Brain of the Firm as an analogy of the human nervous system, however the team's task was to apply it to government agencies, such as CORFO, its industrial committees and their enterprises; the challenge was understanding these agencies and enterprises as recursive parts of an organizational system. ${ }^{1}$ How could we see them as integrated systems rather than as fragments of the Chilean industrial economy? How could we understand enterprises' resources and managers as contributors to systems 1, 2, 3, 4 and 5? Did it make sense to consider the finance department of an enterprise as an operational system (i.e. autonomous system 1)? What was the systemic meaning of an enterprise function, such as quality control, in a manufacturing factory? Was this quality function part of system 1 or of system 3, or for that matter of System 4? Which activities had to be included in a plant's quantified flowchart? How to observe relationships between people and resources? At an aggregated level it was relatively easy to break down a factory's transformations into input-output activities. The overall modelling became more difficult when it was unclear which one was the system in focus; were we talking of an industrial sector, or a plant within an enterprise; which were the recursion levels of the industrial economy? Which resources were focused on the outside and then (i.e. longterm) and which were focused on the inside and now (i.e. short-term)? The answers to these questions, and of a huge number of others, were not explained in Brain of the Firm. We either asked these questions directly to the model's creator or made the effort to understand and disentangle them by studying the book itself. Of course, we did both. However, the team spent significant time trying to clarify the book's ideas. Much learning took place and producing answers to these questions was one of my contributions to Cybersyn (Espejo 1973).

\section{Cybersyn's evolution; performance indices and executive information systems}

After the coup in September 1973, I moved to the UK and for many years I developed a strong and most valuable relationship with Stafford. He could see that people reading his work were amazed by his insights about communications and complexity, but also were asking for his help to use them. From 1975 to 1985 he wrote three additional books about the VSM and in particular in the last of these books Diagnosing the System for Organizations (Beer 1985) he offered practical guidance to apply the Model. This book was well received but still people in companies wanted

\footnotetext{
${ }^{1}$ See Beer (1979) and the book Organizational Systems (Espejo and Reyes 2011).
}

further support. I got involved in several projects to help in these applications. However, it became clear to me that still more clarification was necessary to make them applicable. The quest for answers to the questions emerging during the Cybersyn Project required further attention.

Answering these questions, some of them well structured, others hazy and unclear became part of my research interests too. They gave impetus to my methodological work, which, as I explain later, triggered my work in the VIPLAN method and methodology until today (Espejo 2020).

Before going deeper into this methodological work I want to explain further developments emerging from the Cybersyn project after 1973. Previous publications, in particular in Beer's Brain of the Firm second edition (Beer 1981), detailed its four activities; Cybernet, the telex network along the country providing electronic communications between industries, enterprises and the government at large, Cyberstride, a software for data processing of indices of performance in real time, aimed at alerting workers and managers about significant changes in plants, enterprises and industrial sectors, CHECO, relating the performance of enterprises and industrial sectors to the macro economy, in particular to visions of their future in the industry and economy, and the Operations Room, to create a decision environment balancing short-term achievements with long-term trends in an ergonomically designed room for conversations.

These four developments of Cybersyn are discussed in Beer (1981) and I have discussed them in several publications over the past 40 years (Espejo, 2008, 2009, 2014, 2017). Commentators have criticized Cybersyn as Science Fiction (see for instance https://www.wosc2020.org/videos), which made visible some of its implementation shortcomings. While some of these criticisms may have been just, many of them failed to recognise that the huge contribution of Cybersyn was the Viable System Model and not its technological prowess. This model contributed then and is contributing today to the management of interactions in our digital societies. It is profoundly imaginative, solid and anticipatory of current developments. Cybersyn, and in general the work in Chile, helped its consolidation starting from the early 1960s. Some commentators have argued that an operations room with ample and comfortable chairs for conversations but without tools to communicate the outcomes of these conversations to the outside world, that is, to communicate policy-makers' decisions to stakeholders, suggested a reduced conceptual design. This shortcoming was captured by a cartoon of the New Yorker in October, 2018 (see Fig. 2).

Too much display of information and few aspects to communicate decisions out of the room, suggested that the room's design offered a reduced action capacity. For an observer with limited understanding of its cybernetic conception this might have been a fair criticism, which captured 


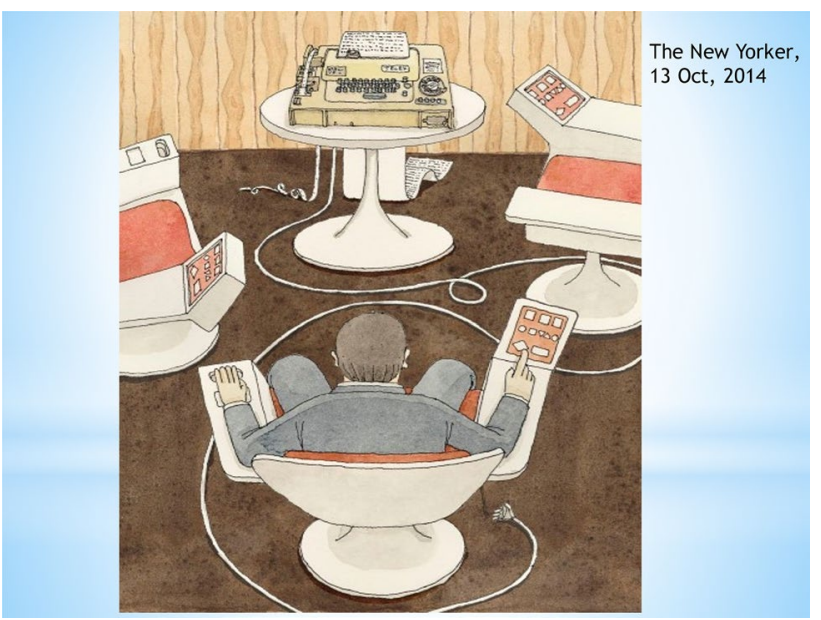

Fig. 2 undefined

the speedy developments of the last few months of the project. However, these shortcomings of the operations room did not invalidate its innovative conception as proved by later developments in Europe and elsewhere (Bittlestone 2010). The Viable System Model, as I explore later in this paper, has remained from those days an important contribution to organisations. Furthermore, this model has opened new paradigms for complexity management of uncontrolled 'big data' and furthermore for countering the damages of fragmentation.

\section{Real-time management and variety engineering}

A significant aspect of Cybersyn was its focus on real-time management; this support to managers was the purpose of Cyberstride. More than transmitting information Cybersyn's design was focused on communications between stakeholders, people and decision makers. The purpose was reporting to managers and policy makers, as close as possible in realtime, productivity and achievement exceptions; indeed in practice data and reports were transmitted with few days of delay; we called this "almost real time". The most significant resources of Cybersyn went in the direction of creating "real time" tools. Industrial engineers in multiple enterprises and industrial committees were flowcharting their input-output operational activities and agreeing with managers and workers key performance indicators (KPI) to run their enterprises, which required transmitting data through Cybernet to the Operations Room in CORFO and then to the National Computer Enterprise (ECOM), for their processing. This processing was done by the Cyberstride computer suite and them reported as exception reports to the appropriate decision makers whenever these emerged.
After the coup, those of us who were closely involved with Cyberstride continued working in its development outside Chile. This was a central focus of my work for several years, until the mid 1980's; key issues were further methodological developments to design performance indices and to design and implement software for data processing in microcomputers. By the late 1970s early versions of Apple microcomputers were already in the market. Significant efforts of some of my students at Aston University in the UK helped implementing new versions of the software, now with the name Cyberfilter, based on the original Cyberstride. Progress was made in public and private enterprises and several of them became interested in supporting its implementation in their organisations. By the mid 1980s I created at the Aston Science Park the enterprise Syncho Ltd; Stafford was its Chairman for many years. Its purpose was further developing and implementing Cyberfilter in enterprises such as Middlesex Local Authority in the UK, the Plastics Division of Hoechst AG in Germany, Hydro Aluminium in Norway, 3M in Europe and others. It became increasingly clear, as implementation of the software was in progress, that these enterprises were more interested in receiving help to model their organisational structures than in the software itself. They wanted methodological help to generate key performance indicators but their main interest was an improved understanding of the cybernetics of their organisations. Our clients were mainly large organisations with significant information system departments, possessing computer resources and skills of their own, capable of carrying out software developments without Syncho's intervention, however they lacked skills for understanding their enterprises as organisational systems, in short they lacked skills for the application of the VSM, and that became the main focus of Syncho's work with them.

In parallel to these projects there were several research groups in Europe and worldwide, interested in similar technical developments to those anticipated by Cyberstride. Performance indicators, as had been proposed by the Cybersyn project, detecting change in real time were very attractive in those days and became commonplace later on. "Executive information systems' ' attracted the interest of several companies and people wanted to further the idea supported by emerging software and modelling technologies. In the UK Robert Bittlestone (2010), created the company Metapraxis (https://www.metapraxis.com) and with the advice of Stafford in their board they offered information services to large companies and in particular they specialised in implementing management decision rooms worldwide. In the USA, important work related to executive information systems was taking place at the Harvard Business School (Kaplan and Norton 1996) at that time. It is in this context of global interest that Victor Ganón from Uruguay, together with a team of local engineers and statisticians, approached Stafford to 
implement a cybernetic project for the management of the country's National Government. While they had an overall interest in organisational cybernetics their main focus was on developing competencies for key performance indicators and in particular for the short-term forecasting statistical model that had been used in Chile. They made important developments using the Bayesian forecasting model (Harrison and Stevens 1971) to track performance indices in real time for the president's office of Uruguay. The book No hay gato: URUCIB y la transformación del Estado (Ganon 2019) offers an excellent account of this project, with President Julio Maria Sanguinetti as the main client. Though Ganon's group had an interest in the overall cybernetics of the government, in the end their main achievement was the implementation of Cyberfilter in Uruguay. As Syncho Ltd. was evolving towards the application of the Viable System Model in enterprises, URUCIB's was evolving towards the software for real-time management of the country's economy. Stafford's work had been related to these developments, however as Ganon's work evolved more in the direction of executive information systems Beer interest in pursuing the Uruguayan project diminished. In the end it was more about management information systems than about the cybernetic transformation of the national economy. It can be argued that it was an important information management project in Latin America but failed to see the issues of organisational transformation supported by the VSM.

After reading Ganon's book and receiving his comments about one of my personal accounts of Cybersyn (Espejo 2017) I replied to him in December 2019 saying;

I am left with the impression that the most important achievements (in Uruguay) were Ciberfiltro and the Management Center, which in terms of the late 1980s and early 1990s, we called Executive Information Systems (EIS).

These results impressed me greatly; Your communications and conversations with President Sanguinetti and the support he gave to the URICIB project were very important and perhaps unique for a cybernetic project at the Presidential level of a country.

Discussions in the 7th floor of the Libertador building impressed me and showed that you influenced decisions at the national level and most likely that this influence went beyond the Presidency, to state companies. However, I did not find discussions and results related to the VSM.

It is mentioned in several places but I did not read discussions about its relevance to the governance of Uruguay, including its influence on the structural foundations of the country's companies and institutions.
It was undoubtedly a templete for the application of an EIS, but nothing is said about aspects of variety, ${ }^{2}$ explaining how strategies of attenuation and amplification of variety (which you refer to in page 40) could be used to strengthen the influence of employees and workers in the state and business executives.

An EIS may have helped to develop a more efficient but not necessarily a more effective society and as you recognize at the beginning of the book, cybernetics is the science of effective organization... Knowing Stafford and his work in Chile, I was surprised that he did not insist with you to apply variety engineering as a central aspect of URICIB.

Lack of work on this aspect, which is central to the VSM, reduced the model to an information system and not to an instrument to balance power between the government and companies. In your comment to my Cybersyn article, you say that the emphasis on balances of varieties could have ideologized the model and cybernetics. This is not the case: to recognize that the variety of local units in a company is potentially high, and that its management should be facilitated (by amplification or attenuation is not to ideologize the model, but it is to recognize that business managers use tacitly or explicitly strategies to manage their complexity; often they do this with coercive measures of variety reduction, which was what happened in the Soviet system ..., and it is also what is happening in our neo-capitalist economic system today, which continues to use hierarchies as a strategy to balance varieties.

Naturally, in the end, as we go for one strategy or the other we make apparent our ideology. In Chile Cybersyn clearly leaned towards a socialist strategy of managing variety in the communities and companies and that was an option for good cybernetics rather than blind ideology.

Contrary to the developments in Uruguay, Syncho's work left in the hands of customers aspects of information management and focused its contribution on cybernetic transformation, in particular on variety engineering and governance.

Considering the huge latent and actual complexities of social situations, interactions towards achieving desirable purposes and values can benefit from the idea of variety engineering, which helps articulating the notion of power relationships in organisations. ${ }^{3}$ For agreed purposes those

\footnotetext{
${ }^{2}$ Variety. Following Ashby's work (Ashby 1964) is the term we use to measure and manage situational complexity; variety is the number of possible states of relevant situations.

${ }^{3}$ In this paper I use the idea of 'big data' as a proxy for variety. This idea has been developed by Zuboff in her several publications about Surveillance Capitalism- She says "Surveillance Capitalism establishes a new form of power in which contract and the rule of law are
} 
actors making more situational distinctions and possessing more affordances in organisational interactions have more influence in the outcomes. 'Big data' is important in this argument. As Zuboff writes "The technology trajectory however is clear; more and more data will be generated by individuals and will persist under the control of others" (Zuboff 2015, p75)".

'Big data' is proliferating in our moment-to-moment interactions, which are increasingly controlled by digital enterprises such as Google, Facebook and others. These enterprises are responsible for surveillance transactions in our moment-to-moment choices, actions and decisions. Most of the time we are not aware of the extent to which these enterprises are checking transactions through current developments such as simple and advanced artificial intelligence (AI), ubiquitous algorithms, machine learning and also deep organisational learning. Proliferation of 'big data', that is variety, can be beneficial but also negative. Among beneficial aspects we can argue that the more distinctions we make about a situation the more clear will be for us the options available to reduce, say, the environmental negative impacts of our actions in climate change, or the better will be the detailed management of natural resources or the more focused will be our individual management of health challenges such as COVID. But also they can have negative aspects such as biometric mass surveillance of behaviours, face recognition and others with significant ethical implications. In the literature there are references to good and bad data, and their regulation is a significant domain of current research (Zuboff 2015, 2019; Kahneman et al. 2021). From the perspective of organisational cybernetics and in particular of the work initiated in Chile these aspects of data proliferation and regulation can be studied systemically with variety engineering in the relations between people, organizations and environments, as shown in Fig. 3 (Espejo and Reyes 2011).

This figure shows the imbalances of varieties between the environment, which possesses the largest variety, followed by the varieties of the organization and management $(\mathrm{Ve}>\mathrm{Vo}>\mathrm{Vm}$ ). The management of these varieties is principally based in self-organisation and self-regulation, which are responsible for absorbing most of the variety within the environment, organisation and management themselves. The seven horizontal lines before the environment is an impressionistic measurement of the environmental variety that is reduced to three lines before the organisation. This is the

\section{Footnote 3 (continued)}

supplanted by the rewards and punishments of a new kind of invisible hand (Zuboff 2015, p 82)" "Power is now identified with the means to change the behaviour of people and not with the control of the means of production. Privacy rights thus confer decision rights; privacy enables a decision as to where one wants to be in the spectrum between secrecy and transparency in each situation" (idem p 83).

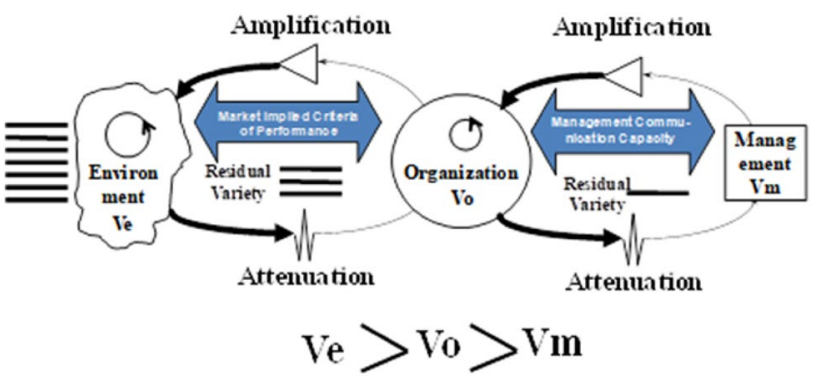

Fig. 3 Variety engineering of environment, organization (BB) and management interactions with variety imbalances within the environment and the organization). Source, Espejo and Reyes (2011)

residual variety that the organisation has to absorb to manage the environmental complexity. Similarly the three horizontal varieties before the organisation is an impressionistic measurement of the complexity that this organisation has to deal with, which is reduced by self-organisation and selfregulation to one, which is the residual variety that management has to deal with to achieve desirable outcomes.

Variety engineering offers conceptual tools so far unexplored in the social domain. In organisational systems it offers means to discuss the regulation of variety proliferation in relational terms between environment, organisation and management, and thereby explores in more depth, as will be discussed below, relationships and relations between people and technology towards regulating the services and possible abuses of the digital enterprises. This topic deserves a good deal of research, in particular towards the design of more humane and ethical relationships, however, here I illustrate briefly, and in simple terms, how we can benefit today from the conceptual developments underpinning Cybersyn, in particular the Law of Requisite Variety (Ashby 1964).

For the purpose of managing complexity we use black box and operational descriptions of organisational systems (Espejo and Reyes 2011).

A black box description is used to measure and manage the relational complexity of management with the organisational system and of this with its environment when there is agreement about the system's purposes; variety is proposed as a proxy to measure today's big data. The black box description is presented in Fig. 4 below which assumes individuals sharing the system's purpose.

An operational description of the interactions within an organisational system clarifies its relationships and the complexity affecting its performance. These relationships are modelled by the Viable System Model, as described in Fig. 5.

Agreement about purposes implies that the black box has a shared observer of its inputs to and of the outputs from the organisational system. This is referred to as first order cybernetics or the cybernetics of the observed system. 


\section{Management of Complexity and Requisite Variety}

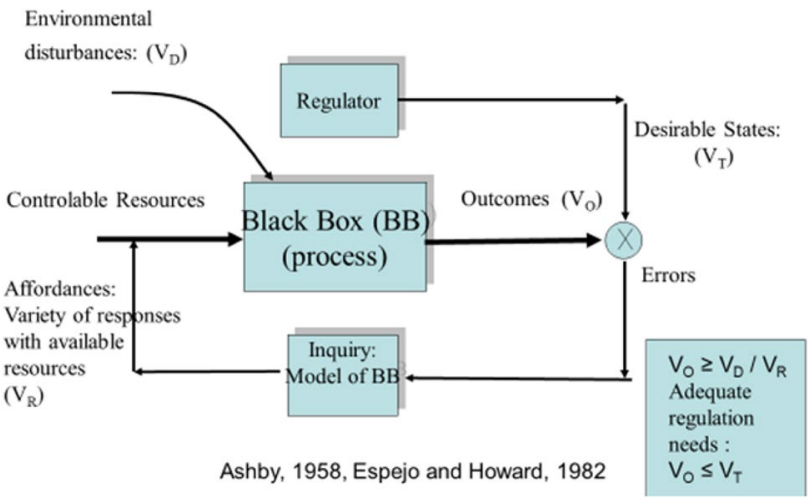

Fig. 4 Management of complexity and requisite variety. Own source to manage disturbances from their relevant environments $\left(\mathrm{V}_{\mathrm{D})}\right.$, that is, in the context of current digital technology, the challenge is managing the 'big data' of their transactions with others through digital enterprises, such as google, Facebook, LinkedIn and others, whether the 'big data' comes from artificial intelligence applications, algorithms or any other form that affect the system's behaviour. This is a black boxes experiencing environmental buffetings, for which their regulators have to produce responses $\left(\mathrm{V}_{\mathrm{R}}\right)$. The outcomes $\left(\mathrm{V}_{\mathrm{O}}\right)$ of these responses to the environmental buffetings are compared with acceptable/desirable states $\left(\mathrm{V}_{\mathrm{T}}\right)$, that is, with regulated purposeful states. Ashby's Law of Requisite Variety tells us that the variety of the black box's outcomes $\left(\mathrm{V}_{\mathrm{O}}\right)$ is always larger or equal than the ratio between the varieties of disturbances and responses $\left(V_{O} \geq V_{D} / V_{R}\right)$ and, most importantly, that for effective regulation $V_{O}$ should be contained within the variety of desirable states $\mathrm{V}_{\mathrm{T}}$. If that
Fig. 5 Operational descriptions: VSM focus on relationships. Own source

\section{VSM Operational Description: Focus on Relationships}

\author{
Relationships: \\ 1. Performance, \\ Productivity, Latency \\ 2. Cohesion, \\ coordination, audit, \\ resources bargaining \\ 3. Policy, \\ cohesion, intelligence \\ policy \\ 4. Inclusion \\ 5. Organisational Citizenship
}

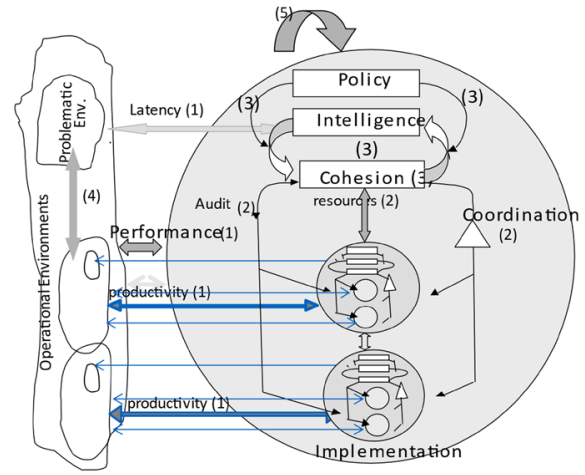

On the other hand operational descriptions are focused on the relationships producing a viable system towards achieving its purposes. These relationships are the outcome of mutually reflexive people observing each other's contribution to the construction of this system. This reflexivity is about the cybernetics of observing systems and is an instance of second-order cybernetics.

In summary, epistemologically black box descriptions relate to first order cybernetics and operational descriptions to second-order cybernetics. In what follows I argue these two forms of descriptions as complementary.

The black box description of Fig. 4 shares the regulatory purposes of the Regulator $\left(\mathrm{V}_{\mathrm{T}}\right){ }^{4} \mathrm{I}$ apply the idea of Black Box to organizational systems, whether they are autonomous people, enterprises or nations. The challenge for them is

\footnotetext{
${ }^{4} \mathrm{VT}$ is the variety of the target set, or the variety of the desirable states related to the shared purposes. The other 'V's in this explanation of Fig. 4 are all explained in the text.
}

is not the case, errors will trigger inquiries, to produce new responses $\left(V_{R}\right)$. These responses can be seen as producing affordances to bring back the black box under control. This simple loop helps to visualise the requirements to bring big data under control. Of course often organisational systems lack affordances and therefore environmental disturbances and technological developments override our purposes and values. These failures of regulation are all too common today.

From a design perspective, bringing these situations under control requires variety engineering, that is, amplification and attenuation of situational variety, with the support of error detection, inquiries and the design of affordances to achieve desirable performance. These are learning loops. This engineering, is explained in Espejo and Reyes (2011) and requires: 
1. Attenuating situational variety without destroying the autonomy of the components producing the Black Box, an issue that we will see is at the core of operational descriptions. This destruction happens with hierarchical structures such as those that existed in the Soviet Union or most likely exist today in capitalist enterprises. Surveillance Capitalism produces inequalities between those who control resources and those who need them to satisfy their needs in capitalist societies (Zuboff 2020). This is often related to the operation of the markets. This variety attenuating strategy requires increasing as far as practically possible the self-organisation and selfregulation of processes in the environment and also in the Black Box (see Fig. 3). This strategy should manage the residual variety in the interactions between the environment and the BB and between this BB and its management (idem). These variety operators could be processes such as actors' coordinating their actions, supported by mutual collaboration and solidarity and trust building within the situation. They are the operational descriptions that are discussed next. Indeed selforganisation and self-regulation, deal with most of the variety within problematic situations making more likely that individuals will have requisite variety to deal with a highly reduced residual variety, rather than with the full complexity of an unregulated situation (this circular loop is the meaning of $\mathrm{O}$ in Fig. 3). More precisely, selforganisation and self-regulation reduce significantly the required response variety of management and organisations to achieve requisite variety vis-à-vis the organisational and environmental complexities respectively. In today's world of digital technology and big data, residual variety can be an outcome of a symbiotic strategy to make more effective situational interactions and communication.

2. Managing residual variety with the support of variety attenuators and amplifiers in between management, organisation and environment (see Fig. 3). All these are processes that require information filters, communication devices and so forth as is further explained below. Learning about the management of residual variety in situations proliferating data is of great significance in surveillance capitalism. They reduce problems for the alignment of situational complexities towards producing desirable transformations. Examples of variety engineering can be found in Espejo and Reyes (2011) (e.g. see p 70).

3. The above strategies are a variety of engineering requirements for the Black Box to achieve balanced interactions in its environment (see Figs. 3 and 4). The aim for the organisational system is absorbing its environmental complexity through adequate performance. The variety engineering model is a learning model that needs to be in constant evolution supported by new scientific models, technologies and possibly social networks to allow the enterprise to monitor its achievements, latencies and performance. These are indeed concerns of big data management as explored in the Viplan Methodology below. Variety engineering is a requirement for the good governance of organisational systems, at all recursion levels from local enterprises to governments.

4. However, in addition to inner self-organisation and self-regulation in the BB and the environment, the BB balanced interactions with its environment happen in meta-systemic contexts, which we call self-developing reflexive environments (Espejo and Lepskiy 2020). This is a cultural contextual environment that provides variety for the interactions in between the organization and its environment and between management and its organization. For instance aspects of national political and economic regulations, changes in social values, trends in innovation and many more provide to different degrees contexts for particular organizational variety balances, which may support variety engineering, or indeed may make it more challenging. An example of this is the case of health in which relational social innovations may reduce the residual variety that needs the attention of the Health Services. A cultural development which incentivises people's local responses to health problems will reduce their dependence on health services and consequently increase self-regulation and self-organisation in the community and reduce the residual variety that needs the attention of health services. These are meta contextual mechanisms for sustainable development necessary to consider in these discussions. Indeed, as I will explore briefly at the end of this paper, this kind of response emerged as necessary at the end of the Cybersyn project.

This last point makes clear that however useful the black box description of an organisational system is to measure its complexity vis-à-vis the environment, the second description, and more fundamental description, is the 'operational description'. This is the one that recognises the moment-tomoment operations within the organisational system, recognises the interactions of actors among themselves and with agents in their immediate environment (Espejo and Reyes 2011) and recognises the cultural, contextual meta-systemic operational interactions with their wider reflexive environments (Espejo and Lepskiy 2020). In these references we have argued that the BB and operational descriptions are complementary. Operational descriptions are descriptions of the relationships producing shared purposes and coordinated actions. They permit discussing its governance and how to improve the management of the interactions of the black box with its environment. This is my understanding of the 
Viable System Model after all these years since Cybersyn (see Fig. 5). From the recursive nature of the VSM it can be expected that the evolving organisational systems will contain operational activities consistent with the purposes and values of the BB description, grounded in the intertwining of people and digital technologies of particular significance in the management of environmental complexity. This is a necessary design of mechanisms to manage the complexity of the relationships of social processes in the context of a co-evolving environment. These are the governance mechanisms of a viable system.

These governance relationships are explained in Fig. 5. The numbers in this figure are the same as the numbers in the paragraphs that follow:

1. Relationship of performance, productivity and latency between actors striving for innovation and producing products, services and externalities with external stakeholders or agents. These are the actors constituting the productivity relationship through policy implementation and those actors constituting the latency relationship, concerned with the outside and then of the organizational system. The latter are relationships in which organisational actors are stretched by stakeholders in the problematic environment. At the extremes this relationship may be controlled by greedy lobbyists, vociferous unrepresentative minorities and conservative bureaucrats or in a more favourable perspective by the viewpoints of empowered autonomous actors, enlightened entrepreneurs and innovative bureaucracies. This stretching puts pressure on both policy makers to invent new responses to changes in the status quo and on stakeholders to recognize their responsibility in triggering this change.

2. Relationship of cohesion between all the actors constituting the organization (e.g. policy makers, experts, civil servants, administrators, employees within the primary activities); in the extreme these relationships can be governed by the authoritarian tendencies of those in power, imposing hierarchical relationships, or by the mutual respect among all actors that enables autonomy within a cohesive organization, that is, enable heterarchical relationships. These variety operators could be processes such as actors' coordination of actions with others, their collaboration and solidarity, trust building within the situation and others.

3. Relationship of Policy Making, between policy makers and those actors focused on the outside and then, (intelligence actors) and those actors focused on the inside and now (cohesion actors are all people in the organisational system). Policy-makers' role is to orchestrate conversations between both viewpoints and based on the leadership of desirable purposes and values, they should recognise which conversations are necessary to create robust policies. A key role of policy makers is working out who are these relevant people that should participate in policy debates.
4. Relationship of Inclusion between policy makers and the owners of the organizational system, that is, the people to whom these policy makers are accountable; as President Allende said in the case of Cybersyn these stakeholders were the People. In particular, these are relationships of inclusion and legitimacy which suggest a relationship of social ownership of the organizational system.

5. Relationship of organizational citizenship between the organizational actors and those providing normative context to their activities, for example, those in society who are guardians of societal values. These are the self-developing reflexive environments, constituted among others by metasystemic regulators of the organisational systems. These are the meta-systemic operators constituting the variety operators in between management, organisational system and environment (see Figs. 3 and 4).

The overall relationship between the organizational system and stakeholders is the relationship of performance (1), which is constituted by the relationships of productivity and latency. Through the relationships of policy (3) stakeholders influence the identity of the organizational system as they elect representatives that reflect their purposes and values.

For a more direct influence of the problematic environment in the relationship 4 of Fig. 5, these external stakeholders can directly leverage their power, firstly through their moment-to-moment communications with stakeholders in the system's operational environment (4), who are in productivity relationships (1) within those producing this system and secondly through their dialogues and other forms of engagement with the system's intelligence actors responsible for its latency through the stretching relationship (1).

It is apparent that the governance relationships go far beyond the executive information systems which were proposed by Cyberstride and URUCIB. The Viable System Model evolving from the Cybersyn Project suggests more fundamental questions rooted in the variety balances of this model. Key for data management and problem solving is correcting variety imbalances between managers at different structural levels within the organisational systems and between them and their data environments, that is, these are relationship questions related to variety engineering. In summary for governance:

1. How does the law of requisite variety anticipate the affordance necessary to increase the quality of organisational responses to environmental complexity and regulatory requirements for performance?

2. How to overcome institutional fragmentation through self-regulation and self-organisation towards achieving desirable performance?

3. How can the Viable System Model support conversational and interactive processes for the creation, implementation and regulation of desirable policies? 
4. How can bottom-up and heterarchical interactions, intertwined with digital technology, support selfregulation and self-organisation and the emergence of organisational systems?

5. How can effective interactions make more balanced and equal power relationships in organisational systems?

6. How can we centralise and/or decentralise resources and functions to achieve more effective performance?

7. How can structure and communications enhance the liquidity of an organisational system, that is, change its boundaries to respond more effectively to distributed technological demands?

8. How can we increase the capabilities of an organisational system for adaptation in a changing environment?

9. Who are and how can environmental stakeholders be included in policy processes?

10. How can we make governance more sensitive to an organisational system's ecology?

\section{From the Viplan method to the Viplan methodology}

Beyond Cyberfilter and executive information systems my work evolved towards a deeper understanding of the VSM, ${ }^{5}$ starting with the Viplan method. This evolution had its origin in my work as operations director of the project in Chile. The methodological questions I asked to myself while working in Cybersyn remained in my mind beyond the technical aspects of real-time.

I was fortunate to collaborate with Stafford as he was writing the methodological book Diagnosing the System for Organisations in 1985. At the same time in collaboration with students and colleagues at Aston University and Syncho Ltd. I produced several diagnostic monographs of small organisations in the United Kingdom. In particular $P M$ Manufacturers (Raul Espejo 1983, 1989a, b) was at the core of my work in the Viplan Method. The detailed application of the VSM to this enterprise helped clarify its application. At the same time I was interacting with Peter Checkland of Lancaster University (Checkland 1981) and learned from him the huge relevance of clarifying organisational purposes to measure the complexity of black boxes and study an enterprise's structure; he talked about naming systems. This was the beginning of developing the VIPLAN method

\footnotetext{
5 The original focus was on the Viplan Method, which soon evolved into a methodology (Espejo 1993). The complementarity of the Viplan Method and the Viplan Methodology was further developed in Espejo and Reyes $(2011,2016)$ and more recently in several publications, in particular Espejo (2020).
}

to study organisations, which was published in 1989 in my co-edited book "The Viable System Model: Interpretations and Applications of Stafford Beer's Model" (Espejo and Harnden 1989). The VIPLAN Method was introduced in the chapter A Cybernetic Method to study organisations.

VIPLAN was proposed as a method to measure the complexity of an organisation's transformation starting from naming the organisation as a system with inputs and outputs. Its emphasis was a Black Box description. The method started with naming its transformation of inputs into outputs. I proposed the mnemonic TASCOI as a shorthand to relate the transformation (T) of suppliers' inputs (S) to actors (A) to produce customers' outputs $(\mathrm{C})$, regulated by owners $(\mathrm{O})$, operating in the context of interveners (I). This initial idea was used to develop in full the Viplan method and software (Bowling and Espejo 1996). This method was further developed by colleagues and students in hundreds of projects throughout the world. In particular they were used and further developed by two of my Colombian colleagues; Angela Espinosa and Alfonso Reyes. Following Angela's initiative at the Colombian National Audit Office CGR, I proposed a project about second-order auditing, where VIPLAN was used in full (Bula 2004; Espejo 1998; Reyes 2001). This was a significant application of organisational cybernetics in Latin America from 1995 to 1998. Alfonso was a major contributor in the process of furthering the development of the Viplan Method. With him I wrote the book Organizational Systems: Managing Complexity with the Viable System Model (Espejo and Reyes 2011), which in 2016 was published in Spanish by the Universities of Los Andes and Ibague in Colombia. ${ }^{6}$ The methodology I used, at a later stage, at the CGR was the Viplan Methodology, which I first published in 1993 (Espejo and Schwaninger 1993), as a problem solving methodology. It was focused on improving organisational people's interactions to respond to problematic situations. Graphically the Viplan Methodology is built upon two concentric learning loops as shown in Fig. 6 (see Espejo 2020).

In this methodology:

- The cybernetic inner loop contributes to improve the structure of the organisational systems dealing with problematic situations through a circular diagnosis of the quality of conversations and communications, which may produce more or less responsibility, as they deal with issues such a good performance of enterprises or as in the Cybersyn case, the better performance of the economy of a country. An adequate performance requires building up good structural conversations, or what we may call here, they need good cybernetics to handle these problem situations effectively. The cybernetic -inner- loop

\footnotetext{
${ }^{6}$ Raul Espejo y Alfonso Reyes, 2016. Sistemas Organizacionales: El Manejo de la Complejidad con el Modelo del Sistema Viable. Universidad de Los Andes, Universidad de Ibague. See link https://uniandes. ipublishcentral.com/product/sistemas-organizacionales.
} 


\section{Viplan Methodology and Problematic Situations}

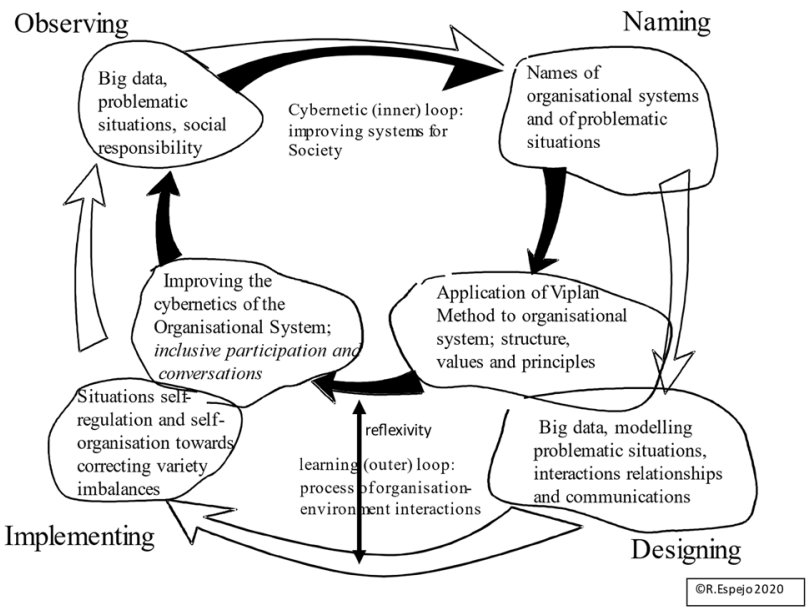

Fig. 6 The Viplan methodology and problem situations (adapted from Espejo 2020)

is meta to the stakeholders' problem solving interactions vis-avis a problematic situation, such as climate change! The quality of their communications, relationships and conversations is self-defined in the context of societal and organisational purposes. These structures may either facilitate or inhibit, to different degrees, problem solving processes. The purpose of the cybernetic -inner- loop is to promote good cybernetics, that is, to make organisational communications effective. An improved cybernetics is necessary to produce desirable performance (e.g. social responsibility) and facilitates effective conversations, or in other words it opens the space for including stakeholders in problem situations and therefore for producing better democratic processes.

- In the learning-outer loop- participants take advantage of the enabling structures emerging from their inner loop, to engage in processes of continued conversations and learning about relevant situations, including 'big data' challenges. They engage in mutual interactions to achieve agreements upon any changes that they may wish to make to improve these situations. This outer loop is focused on problem situations that need stronger appreciation and better modelling.

- The two loops are reflexively related in the sense that as the cybernetics of conversations improve in the inner loop, the participants' appreciation of their problem situations becomes more sophisticated in the outer loop and this better appreciation of situations trigger changed conversations and structures in the inner loop, recursively. In either case the aim is building up self-regulation and self-organisation towards correcting variety imbalances as explained before. The overall management of situational problems is achieving requisite variety through variety engineering. This is a fundamental learning process to consider 'big data' in technological developments, artificial intelligence, algorithms and so forth to increase the influence of people and regulators in countering the Surveillance Capitalism prevailing today and most likely to influence even more social developments in the future.

\section{Reflexion about the VSM and complexity management}

\section{1 'Big Data' and variety engineering}

Implementing situational transformation requires correcting variety imbalances in the participants' interactions to achieve desirable purposes. From a design perspective this is the most demanding aspect of problem solving. Correcting these imbalances is the approach to give requisite variety to interactions, produce affordances, and therefore a means to move in the direction of improving situations. These are exercises in variety engineering between organisational actors and between them and environmental agents. In other words it is an exercise in complexity management, which, as explained before, is central to today's 'big data' management. Through the Viable System Model current societies and organisational systems can improve this management.

Cybersyn had at its core the Viable System Model (VSM), which, as explained above, has continued to evolve over the past 50 years. Our increased understanding of complexity management in general and variety engineering in particular as well as the fast development of digital technologies offers new opportunities towards fairer and better societies, but also 'big data' can reduce autonomy, equality and can restrict freedom. In today's digital society, organisational cybernetics offers a revolutionary paradigm to manage these data. In the $70 \mathrm{~s}$ our inability to manage complexity made it extremely difficult to achieve people's coordination of actions and the building of responsible trust without interfering in their autonomy. These technological limitations made hierarchical structures more necessary in communist or capitalist organisations. Not surprisingly executive information systems were easier and are still easier to implement. They are the most attractive to increase the heavy hand of executives but in the end I suggest that it is the VSM's cohesive function, through recursive structures, that is offering better possibilities to support people's coordination of actions and is increasing the opportunities for horizontal interactions among them to make managers' residual variety manageable. The Viable System Model offers a paradigm towards understanding autonomy at as many recursive levels as necessary. Today's digital technology has the potential to support this paradigm with tools to realise autonomy. As already argued, different degrees of hierarchies were the outcome of poor variety engineering or lack of complexity management strategies, as made apparent, by management with inadequate ideological connotations, both in socialist 
and capitalist economies. In the former hierarchies had the ideological undertone of input-output matrices, as they aimed at balancing, albeit unsuccessfully, enterprises interactions; in the latter the ideology of the markets has proved to be more successful in managing black box interactions but at the cost of increased inequalities and an unfair distribution of wealth within the organisational systems. It is taking longer to realise that people will look for fairness and oppose capitalists hierarchies. Capitalism is arriving at the same conclusions (Pikkety 2020). In a global society demanding ethical responses for coordination, trust, fairness, cooperation, collaboration, responsibility for the less well provided and solidarity among nations, these nations are crossing local boundaries and requiring solutions that overcome racial and cultural differences, requiring solutions that overcome among others health, educational, economic and social inequalities. The COVID-19 and also the climate crises are making these implications more evident. Socially, we need to move in the direction of organisational structures that increase autonomy and regulate variety generation at the local level, as suggested by the self-organisation and self-regulation of variety engineering. This trend is already happening through the multiple mechanisms emerging in Internet in the direction of block chains and other technological links that are increasing coordination, perhaps initially with an emphasis in financial coordination but we may expect that, as the demands of sustainability grow, along the United Nations proposed sustainable development goals, coordinating the use of natural resources towards climate action, water resources, sanitation and others and other social management goals will require mechanisms to balance organisational interactions (United Nations 2018). Indeed, the systemic underpinning of these actions are anticipated by the paradigm of the Viable Systems Model.

The digital society and the Viable System Model (VSM) share a focus on complexity as mooted by the Cybersyn project that was grounded in variety management (Ashby 1964). In the digital society activities are grounded in technologies with large capacity to create as well as to map all kinds of situational states, that is, 'big data' activities with great capacity for variety proliferation between enterprises, customers and their environments. Algorithms, artificial intelligence, 3D printing, engineering services and so forth are making it possible for organisational systems to correct variety imbalances with their environments in real time. Rather than dealing with aggregations and averages, these systems match individual but systemic needs through structural and algorithmic models. In other words, on the one hand their services can be tailored to people's specific needs and on the other they can help lift undesirable constraints and abuses of power, like for instance those imposed by hierarchies but also by surveillance capitalism (Zuboff 2015, 2019). People's distributed responses to large environmental challenges should be managed not only at aggregated levels but most significantly at local and individual levels by providers with the support of enabling technologies, adding flexibility and convenience. Computer networks are increasing relational performances beyond what was possible in the last century, through better governance and inclusion overcoming institutional fragmentation and isolation.

The VIPLAN Methodology has been proposed to guide an organisational system to manage its environment's increasing complexity through collaboration and coordination with others, rather than by attempting to go alone in a fragmented fashion. It is in this context that this methodology plays its role. Beyond its use as a modelling tool for organisational systems, it is dealing with situations that require flexibility, creativity and adaptability.

The VSM's appreciation of structures, relationships and interactions opens the space for participation, democracy, and accountability. Cybersyn as a model for democratic viability is offering an opportunity to go beyond 'traditional socialism'; unfortunately it remains a utopia today, even with current progress with digital technology. This utopia is more than technological, it is more a utopia grounded in societies' and enterprises' failure to create desirable relationships, such as heterarchical relationships. People's interactions tend to go along long-term enshrined relationships, that people are not prepared to give up easily. These are social transformations that require imagination and leadership for new relationships. These are situations driven by power structures grounded in centuries of history that people want to preserve. What we are missing today is cultural, ethical and political progress. National opportunism and poor leadership are restricting unnecessarily important relationship transformations. COVID-19 is making apparent the need for this progress. Perhaps their realisation is too optimistic, but we may expect that different local and global forms of interactions will evolve during this pandemic and will give opportunities for new organisational forms (Espejo 2020).

We are increasingly recognising that current social forms need revision. Economists are connecting their language to the need for a transactional world, responsible for new organisational forms. Particularly now, with COVID-19 the anticipation in western societies is that they will experience increasing economic problems which they will transfer to future generations, possibly being an additional factor towards increasing social inequalities (Streeck 2016; Stigletz 2020, Piketty 2019). As argued before, societies will have to respond to this challenge with more collaboration and mutual support. New organisational forms will be necessary to manage social and economic complexities and the VSM anticipates an innovative approach to deal with these challenges.

My argument has been that Cybersyn offered a vision of a new world towards fairer societies. In the 1970s the 
network and digital societies were decades away. After several decades we need to reflect upon their meanings today, taking into account social, economic and technological developments in a world experiencing pandemics and climate change. Beer's imagination was far ahead of the resources and competencies available in the Chile of the 1970s. Despite those limitations as already argued, Cybersyn offered an extraordinary vision. There are times in social history when, in spite of weak embodiments, the utopia of a fairer society with high expectations of solidarity and respect for the less privileged may not be completely farfetched. New scientific ideas, as those triggered by the post second world war Macy conferences on cybernetics (Kline 2015) that anticipated the cybernetics of cognition (Maturana 2002), complexity (Ashby 1964; Shannon and Weaver 1949) and communications (Wiener 1948; von Foerster 1984) need today similar creativity and vision. This is the challenge for today's cyberneticians. Over the years, after the September 1973 coup d'état, the vision of what was happening in those days has been emerging and creating opportunities for a renovated world. For optimists the last $40-50$ years of socio -technological changes are making the longer-term evolution towards a fairer non-hierarchical society more likely. For the less optimistic, this is a misplaced utopia. Which kind of society is the VSM allowing us to think about? What does it mean to be a society with good cybernetics? How can we realise autonomy, innovation, cohesion and responsibility? How can it contribute to a society with more respect and less abuse of power among us? These are questions left open for us in the future.

\section{CODA. A model of capitalism as a context for Cybersyn}

Briefly, I want to go back to the second aspect of working with Stafford in those years. This was a Model of Capitalism. As already anticipated Stafford wrote it in June of 1973, as we were approaching the end of the project Cybersyn. He wrote it during his last visit to Chile and left the manuscript with me; about 55 pages of text intertwined with a set of evolving and interdependent cybernetic diagrams, which in a rough fashion are integrated and presented in Fig. 7 "A Cybernetic Model of Contemporary Capitalism"; this is a draft of Beer's model. Recently this manuscript has been studied by Diego Gomez-Venegas, Chilean doctoral researcher at the Humboldt University of Berlin, who transcribed and re-drew it as a central part of his research. He will be publishing this work in the near future. In my view he has achieved an integration of Beer's narrative with its accompanying diagrams, showing Beer's work as a multimedia kaleidoscope. I'm leaving to him explaining this document, something that I can anticipate will build

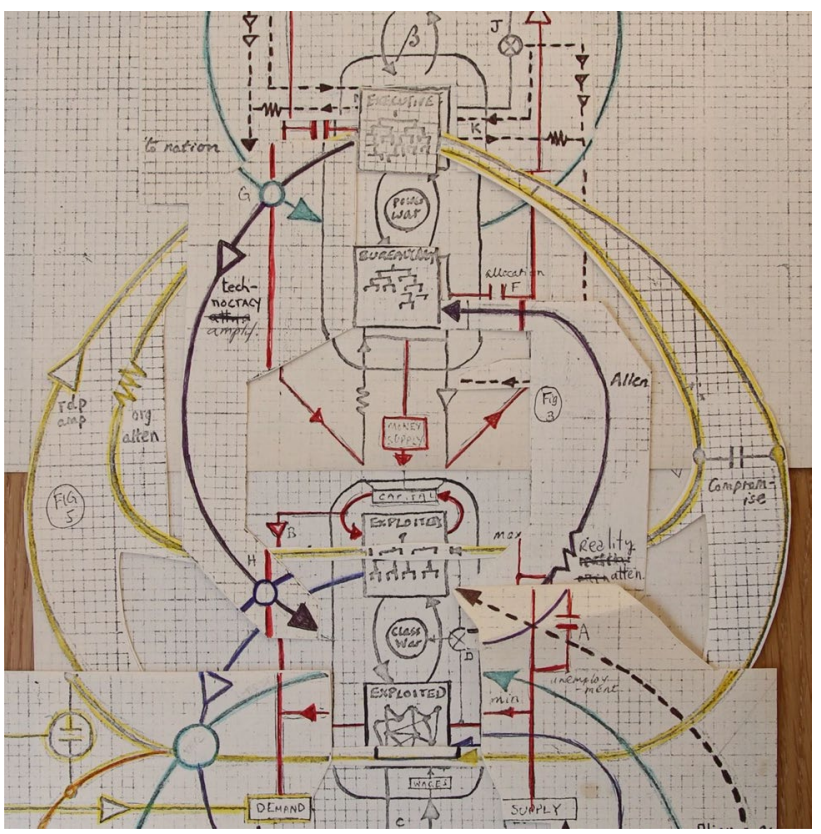

Fig. 7 A cybernetic model of contemporary capitalism. Own source

a meaningful model for today's world, starting from Stafford's discussion of technologies of government, focused on autonomy, homeostatic relationships, metasystems, requisite variety and redundancy of potential command.

From the perspective of my work this model provides the framework for a self-developing reflexive-active environment along the lines of an operational description of organisational systems towards a new form of 'neo-socialism'. Whether Beer's 'model of contemporary capitalism' stands the deeper scrutiny of today's social and economic thinking and policies, is left to be judged by those reading GomezVenegas's discussion of Beer's work, however the above cybernetic concepts are invariant to time and help working out mechanisms for a dynamic social developments. Mariana Mazzucato (2020) has proposed, what she calls 'mission economy' as an alternative model of relations between the public and private sectors, which would benefit from a more explicit recognition of the ideas of good cybernetics, as proposed in this article. But, in general today there is a much more sympathetic view for a socialist economy, triggered by the inequalities of the current capitalist economy and its failure to overcome its implicit poor variety engineering which has maintained a hierarchical structure for the enterprises and economies in societies worldwide. These hierarchical structures are not acceptable in many societies today. Piketty's shout 'Hurrah for Socialism' (Piketty 2020) coming from someone within a social democratic tradition, who wrote Capital in the twenty-first Century (Piketty 2014), himself did not anticipate this transformation of his views. 
From the perspective of this paper, Beer's model of capitalism provides a contextual addition to the self-organisation and self-regulation of Black Boxes and operational descriptions of interactions as discussed earlier in this article. Beer's last contribution to Cybersyn shows that he was aware that the four components of that project-Cybernet, Cyberfilter, CHECO and the Operations Room- were lacking a cybernetic meta-systemic contexts, which he called a contemporary model of capitalism and which today, with the benefit of more recent developments, Lepskiy called Third Order Cybernetics (Lepskiy 2019) with an emphasis in self-developing reflexive environments and that both of us, from the perspectives of the Viplan Methodology and his work, prefer to call Ontological Cybernetics and Social Responsibility (Espejo and Lepskiy 2020). These developments put an emphasis on cultural contextual environments that provide variety for the interactions between organizations and their immediate environments. It is in these wider social and political environmental contexts, that aspects of global, regional, national and local cultural, political and economic regulations, take account of changes in social values, trends in innovation, technology and many more dynamic environmental evolutions, providing contexts for particular organization's variety balances, which need variety engineering. These are mechanisms that are necessary to consider for sustainable development. Indeed, these are necessary considerations to enrich our understanding of a visionary project such as Cybersyn.

\section{References}

Ashby R (1964) An introduction to cybernetics. Methuen \& Co Ltd., London

Barrientos J, Espejo R (1973) Un modelo cibernético para la Dirección del Sector Industrial. INTEC/CORFO 4:5-18

Beer S (1966) Decision and control. The meaning of operational research and management cybernetics. Wiley, Chichester

Beer S (1972) Brain of the firm, 1st edn. Allen Lane The Penguin Press, London

Beer S (1979) The heart of enterprise. Wiley, Chichester

Beer S (1981) Brain of the firm, 2nd edn. Wiley, Chichester

Beer S (1985) Diagnosing the system for organizations. Wiley, Chichester

Beer S (1969) The aborting corporate plan: a cybernetic account of the interface planning and action. In: Paper presented at the perspectives of planning: proceedings of the OECD working symposium on long-range forecasting and planning, Bellagio, Italy

Bittlestone R (2010) Financial management for business: cracking the hidden code. Cambridge University Press, Hardcover Cambridge

Bula G (2004) Observations on the development of cybernetic ideas in Colombia. A tribute to Stafford Beer. In: Tribute to Stafford Beer, R. Espejo, Guest editor of Kybernetes, vol 33 No. 3/4

Checkland P (1981) Systems thinking, systems practice. Wiley, Chichester

Espejo R (1983) Management and information: the complementarity control-autonomy. Cybern Syst 14(1):85-102
Espejo R, Harnden R (eds) (1989) The viable system model: interpretations and applications of Stafford Beer's VSM. Wiley, Chichester

Espejo R (1989b) The VSM revisited. In: Espejo R, Harnden R (eds) The viable system model: interpretations and applications of Stafford Beer's VSM. Wiley, Chichester, pp 77-100

Espejo R, Schwaninger M (eds) (1993) Organizational fitness: Corporate Effectiveness through management cybernetics. Campus Verlag, Frankfurt/New York

Espejo R (2008) Observing organisations: the use of identity and structural archetypes. Int J Appl Syst Stud 2(1/2):6-24

Espejo R (2009) Performance management, the nature of regulation and the CyberSyn project. Kybernetes 38(1/2):65-82

Espejo R (2017) Cybernetic argument for democratic governance: cybersyn and cyberfolk. In: Werner LC (ed) Cybernetics: state of the art, vol 1. Universitätsverlag der TU Berlin, Berlin, pp 34-57

Espejo R, Lepskiy V (2020) An agenda for ontological cybernetics and social responsibity. Kybernetes. https://doi.org/10.1108/K$06=2020-0390$

Espejo R, Reyes A (2001) The state of the state: introduction. Syst Pract Action Res 14(2):135-137

Espejo R, Reyes A (2011) Organizational systems: managing complexity with the viable system model. Springer, Heidelberg

Espejo R, Dominici G (2016). Cybernetics of value cocreation for product development. Syst Think Behav Sci. https://doi.org/10. $1002 /$ sres.2392

Espejo R, Howard N (1982) What is requisite variety? A re-examination of the foundation of Beer's method. In: Working paper series. Management Centre. Aston University, Birmingham

Espejo R, Reyes A (2016) Sistemas organizacionales: El Manejo de la complejidad con el modelo del sistema viable. Universidad de Los Andes, Universidad de Ibague. https://uniandes.ipublishcentral. com/product/sistemas-organizacionales

Espejo R (1973) Proyecto Synco; conceptos y practica del control; una experiencia concreta: la Direccion Industrial en Chile. CORFO, pp. $5-18$

Espejo R (1989a) P.M. manufacturers: the VSM as a diagnostic tool In: Espejo R, Harnden R (eds) The viable system model: interpretations and applications of Stafford Beer's VSM. Wiley, Chichester, pp 103-120

Espejo R (1998) La auditoría en la construcción de un Estado efectivo. En la construcción de un nuevo discurso del control. Reflexiones sobre el proceso de cambio y fortalecimiento institucional 19951998. Contraloría General de la República, Bogotá

Espejo R (2014). Cybernetics of governance: the Cybersyn project 1971-1973. In: Social systems and design, pp 71-90. Springer, New York

Espejo R (2020) The enterprise complexity model: an extension of the viable system model for emerging organisational forms. Syst Res Behav Sci (published as early view) 1-17. https://doi.org/10. 1002/sres.2735

Griffith-Jones S, Sola MLM, Petersen J (2018) The role of CORFO in Chile's development; achievements and challenges. In: CORFO (ed) Omar Miranda

Harrison PJ, Stevens CF (1971) A bayesian approach to short-term forecasting. J Oper Res Soc 22(4):22p

INTEC (1973) Grupo de cibernetica de INTEC y otros especialistas de CORFO. In: Diseño de una sala de operaciones, vol 4, pp 19-28

Kahneman D, Sibony O, Sunstein C (2021) Noise, a flaw in human judgment. Harper Collins, London (in Kindle)

Kaplan R, Norton D (1996) The balanced ScoreCard; translating strategy into action. Harvard Business School Press, Boston

Kline RR (2015) The cybernetics moment or why we call out age the information age. John Hopkins University Press, Baltimore

Maturana H (2002) Autopoiesis, Structural Coupling and Cognition: a History of these and other notions in the biology of cognition Cybernetics \& Human Knowing, Vol. 9 Issue 3-4 Pages 5-34 
Mazzucaton M (2020) Mission Economy. Penguin, Kindle

Piketty T (2014) Capital in the Twenty-First Century. The Belknapk Press of Harvard University, Boston

Piketty T (2020) ;Viva el socialismo!: Crónicas 2016-2020 (D. Fuentes, Trans.). Deusto, Barcelona

Reyes A (2001) Second-order auditing practices. Syst Pract Action Res 14(2):157-180

Shannon C, Weaver W (1949) The Mathematical Theory of Communication. Publisher: University of Illinois Press

Shoshana Z (2015) Big other: surveillance capitalism and the prospects of an information civilization. J Inf Technol 30:75-89

Shoshana Z (2019) The age of surveillance capitalism. Profile Books, London

Stigletz JE (2020) People, power, and profits; progressive capitalism for an age of discontent. Penguin, Kindle version
Streeck W (2016) How will capitalism end: essays on a failing system. Verso, London/New York

United Nations (2018) The sustainable development goals report 2018. United Nations, New York

Von Foerster H (1984) Observing Systems. Publisher: Interpublishers California

Wiener N (1948) Cybernetics: or control and communications in the animal and the machine. The M.I.T. Press, Cambridge

Publisher's Note Springer Nature remains neutral with regard to jurisdictional claims in published maps and institutional affiliations. 